\title{
Educación audiovisual y Cultura audiovisual en la ESO y el Bachillerato
}

\author{
Audiovisual Education and Audiovisual Culture in the ESO and \\ Bachillerato
}

Minerva Campos Rabadán

E $\mid$ perfil y los intereses de quienes han reflexionado con anterioridad sobre lo audiovisual en los planes de estudio en España han condicionado, inevitablemente, sus aproximaciones, el foco y los debates que sus trabajos visibilizan. Con respecto a la cultura y la comunicación audiovisual en la Educación Secundaria Obligatoria (ESO) y el Bachillerato, podemos señalar dos líneas muy claras que se acercan a ellas, cada una por su lado, desde lo cinematográfico y desde el ámbito de la comunicación audiovisual'. En nuestro caso, pensamos lo audiovisual como un marco amplio que integraría la producción cinematográfica (más y menos clásica y convencional), las artes visuales y mediales, los contenidos de los medios de comunicación y todo aquello que de una u otra manera podría definirse a partir de su naturaleza audiovisual. Así, este trabajo analiza los contenidos y competencias que, relacionadas con lo anterior, están presentes en la ESO y el Bachillerato y explora las tensiones que se generan en su relación con otros espacios formativos como la universidad y la Formación Profesional.

La estructura y los planes de estudios actuales son producto de la Ley Orgánica de Ordenación General del Sistema Educativo (LOGSE)², de 1990, que, recordemos, amplió la edad de escolarización obligatoria hasta los dieciséis años y estableció el sistema de cuatro años de Educación Secundaria Obligatoria (ESO) y un Bachillerato, con diferentes modalidades posibles, de dos años. Ya en el currículo de mínimos previsto por la LOGSE para la asignatura de Educación plástica y visual (en la ESO), se incorporaban tímidamente algunos contenidos relacionados con la imagen en movimiento, el audiovisual y el multimedia, que en el Bachillerato tenían un espacio definido y orientado hacia las tecnologías y las estructuras del sistema audiovisual en la asignatura Comunicación audiovisual ${ }^{3}$ (optativa en los itinerarios Tecnológico y de Humanidades y Ciencias Sociales). Más tarde, la Ley Orgánica para la mejora de la calidad educativa (LOE) $)^{4}$ incorporó el término "audiovisual" en el título de la materia Educación plástica, visual y audiovisual (en la ESO) y, en el Bachillerato, sustituyó la asignatura Comunicación audiovisual por la de Cultura audiovisual (como

\footnotetext{
${ }^{1}$ Ver, por ejemplo, Lara, Ruiz y Tarín (2019) y Civil i Serra y Recoder Sellarés (2017).

${ }^{2}$ Ley Orgánica 1/1990.

${ }^{3}$ En un monográfico anterior de Tarbiya dedicado a cultura audiovisual y educación, Francisco Alonso y Alicia Salvador compartían sus aproximaciones y experiencias en la asignatura Comunicación audiovisual, optativa de $1^{\circ}$ de Bachillerato de la LOGSE (Alonso, 2002; Salvador, 2002).

${ }^{4}$ Ley Orgánica 2/2006.
} 
materia de modalidad en los dos itinerarios de Artes), con un planteamiento diferente a Comunicación audiovisual y muy similar al que actualmente presentan Cultura audiovisual I y II, recogidas en los planes de estudios de la Ley Orgánica para la mejora de la calidad educativa (LOMCE)5, de 2013.

Con este planteamiento, en lo que sigue, atenderemos a las asignaturas que, en la ESO y el Bachillerato, han puesto el foco en el audiovisual en cada momento. También, presentaremos una síntesis de los contenidos y competencias propias de las asignaturas Educación plástica, visual y audiovisual y Cultura audiovisual I y II, incluidas en los planes de estudio vigentes, con el objetivo final de subrayar algunos aspectos de su relación con titulaciones afines impartidas como grados universitarios y de Formación Profesional.

\section{Antecedentes y contexto}

Empezamos este recorrido revisando los contenidos y competencias propios de la comunicación audiovisual y la cultura audiovisual en los currículos de la ESO y el Bachillerato desarrollados para las Leyes Orgánicas de Educación ${ }^{6}$ de 1990 $(\text { LOGSE) })^{7}$ y $2006(\text { LOE })^{8}$.

Desde 1990, la presencia del audiovisual ha pasado de ser anecdótica en los contenidos de materias como Educación plástica y visual, en la ESO, a articular bloques de contenidos específicos y visibilizarse en el título: Educación plástica, visual y audiovisual. Del mismo modo, la materia Cultura audiovisual ha equiparado lo audiovisual a otras disciplinas artísticas ya establecidas con anterioridad en el Bachillerato de Artes. La tabla 1 resume los cambios y correspondencias entre estas asignaturas en la LOGSE, la LOE y la LOMCE, vigente?

Más allá de la articulación de estas asignaturas en sus planes de estudios correspondientes, nos interesan los objetivos y contenidos previstos para cada una teniendo en cuenta su orientación más próxima a las artes plásticas o a la estructura del sistema de medios audiovisuales y, en cualquier caso, su vocación más analítica o práctica.

En la LOGSE (1990), Educación plástica y visual era obligatoria en los tres primeros cursos de la ESO y optativa en 4, teniendo en $1^{\circ}$ y $2^{\circ}$ criterios de evaluación comunes. A lo largo de estos cuatro años, los contenidos de naturaleza audiovisual apenas eran referidos en un par de bloques ${ }^{10}$. En el Bloque 1 de $2^{\circ}$ y $3^{\circ}$ de la ESO se hacía mención a cine, televisión, video y nuevas tecnologías: en $2^{\circ}$, en el bloque "El lenguaje visual. Identificación de los distintos lenguajes visuales" $y$, en $3^{\circ}$, en "El lenguaje visual. La imagen como medio de expresión, comunicación y conocimiento". Sin embargo, en ninguno de los dos cursos esta primera aproximación al audiovisual encontraba correspondencia en los

\footnotetext{
${ }^{5}$ Ley Orgánica 8/2013.

${ }^{6}$ Leyes de educación en España desde 1976: Ley Orgánica 5/1980, de 19 de junio, por la que se regula el Estatuto de Centros Escolares (LOECE); Ley Orgánica 8/1985, de 3 de junio, reguladora del Derecho a la Educación (LODE); Ley Orgánica 1/1990, de 3 de octubre de 1990, de Ordenación General del Sistema Educativo (LOGSE); Ley Orgánica 9/1995, de 20 de noviembre, de la participación, la evaluación y el gobierno de los centros docentes (LOPEG); Ley Orgánica 5/2002, de 19 de junio, de las Cualificaciones y de la Formación Profesional (LOCE); Ley Orgánica 10/2002, de 23 de diciembre, de Calidad de la Educación (no entró en vigor); Ley Orgánica 2/2006, de 3 de mayo, de Educación (LOE); Ley Orgánica 8/2013, de 9 de diciembre, para la mejora de la calidad educativa (LOMCE, vigente). Acceso a los textos íntegros en la página web del Ministerio de Educación y Formación Profesional: https://www.todofp.es/profesores/biblioteca-todofp/normativa-de-educacion/leyes-organicas-de-educacio n.html

${ }^{7}$ Resolución de 29 de diciembre de 1992; Real Decreto 1007/1991.

${ }^{8}$ Real Decreto 1467/2007; Real Decreto 1631/2006.

${ }^{9} \mathrm{Al}$ final del artículo, incluimos como anexo los bloques de contenidos de cada una.

${ }^{10}$ Hemos tomado como estudio de caso el desarrollo curricular de la ESO de la Comunidad de Madrid. Última actualización de la norma. Decreto 34/2002.
} 


\section{taphiya $\mathbf{4 8}$}

bloques dedicados a los procedimientos y técnicas, el 5 y el 6, respectivamente, que, en lugar de prestar también atención a los propios de los lenguajes audiovisuales, se limitan a los de las artes plásticas.

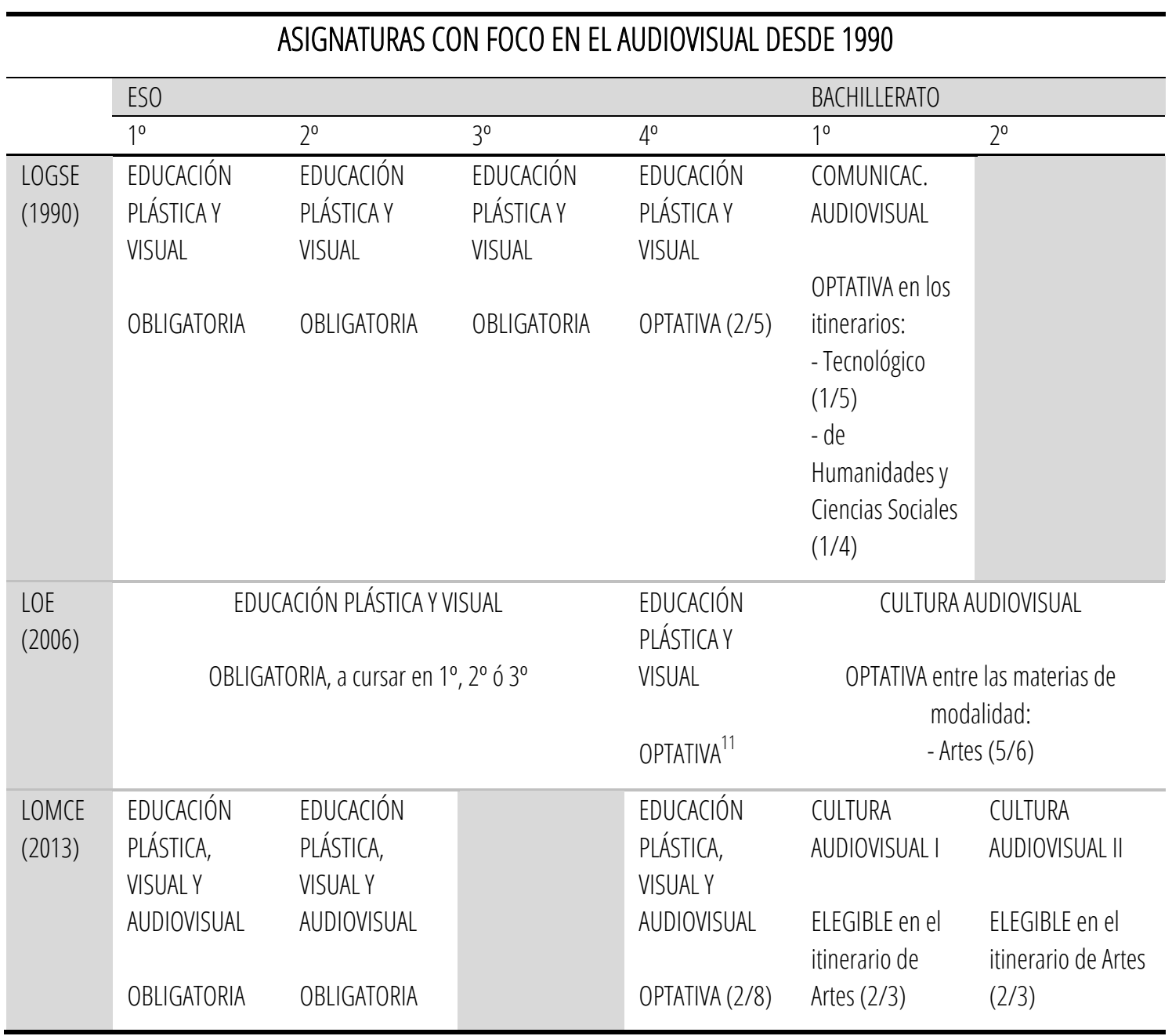

Tabla 1. Asignaturas con foco en el audiovisual desde 1990.

Los bloques en los que se articulaban los contenidos para la asignatura Cultura audiovisual en la LOGSE, optativa de $1^{\circ}$ de Bachillerato en las modalidades Tecnológico y de Humanidades y Ciencias Sociales, son poco descriptivos. Aunque, al atender al desarrollo de cada uno, encontramos que la asignatura se centraba en aspectos relacionados con las tecnologías y técnicas de registro, transmisión, reproducción y distribución en los bloques 1 y 2; dedicaba los bloques 3 y 5 a la teoría de la comunicación y a aspectos como la información, ideología, retroalimentación y audiencias en diferentes medios, la condición de espectáculo y negocio de la radio y la televisión así como las particularidades de la publicidad; y reservaba el Bloque 4 para la narrativa audiovisual (morfología y sintaxis) y la estructura del sistema de medios en el contexto de la televisión y la radio. Como vemos, la asignatura se centraba en elementos contextuales y analíticos más interesados en las estructuras de producción y difusión que en los propios textos, a pesar del bloque

\footnotetext{
${ }^{11}$ Hay tres opciones con tres asignaturas cada una; las y los alumnos pueden cursar las tres asignaturas de una misma opción o cursar dos asignaturas de una opción y una tercera asignatura de una opción diferente.
} 


\section{taphiya $\mathbf{4 8}$}

dedicado a la narrativa audiovisual, que, si bien se mantuvieron en Cultura audiovisual (LOE) y Cultura audiovisual I y II (LOMCE), perdieron mucho peso específico en favor de las competencias interpretativas y analíticas de los propios textos audiovisuales. En este caso, el desarrollo de los contenidos y su orientación tenía que ver con la inclusión de la materia en los itinerarios de Bachillerato Tecnológico y las dos modalidades del de Humanidades y Ciencias Sociales, aunque el planteamiento de Comunicación audiovisual estaba más en sintonía con las Ciencias Sociales que con las Humanidades.

En la LOE (2006), la asignatura Educación plástica y visual se redujo drásticamente en el plan de estudios y pasó a ser una asignatura obligatoria que las estudiantes debían cursar en $1^{\circ}, 2^{\circ} 0$ ó $3^{\circ}$ de la ESO y una asignatura optativa en $4^{0}$ de la ESO. Aunque mantuvo el nombre de Educación plástica y visual, en los dos cursos en los que se impartía incluyó un bloque específico dedicado al audiovisual. En el primer curso de Educación plástica y visual (a superar en los tres primeros cursos de la ESO), los contenidos del Bloque 1 estaban relacionados con la percepción, el lenguaje y la comunicación, la interpretación y la imagen misma; los Bloques 2, 3 y 4 se centraban en los diferentes lenguajes (incluido el audiovisual y multimedia, objeto del tercer bloque), procesos, técnicas y experimentación; y el quinto y último bloque introducía la cuestión de la "valoración" en la asignatura, como rezaba el título del bloque "Lectura y valoración de los referentes artísticos", que no había sido contemplado en el currículo de la LOGSE.

La orientación de la asignatura y los bloques tenían cierta continuidad en la asignatura optativa de $4^{0}$ de la ESO, incluido un bloque específico dedicado al audiovisual, en este caso, Bloque 4: Imagen y sonido, donde los contenidos y competencias a desarrollar tenían un componente más reflexivo y analítico que práctico, al contrario de lo que pareciera indicar su título. En este caso, no existía un quinto bloque dedicado a la valoración similar al de Educación plástica y visual, en el primer tramo de la ESO.

Por su parte, la asignatura Cultura audiovisual era una materia de las dos modalidades de Artes previstas en el Bachillerato de la LOE: Artes plásticas, imagen y diseño y Artes escénicas, música y danza. En su caso, los bloques de contenidos y su desarrollo eran muy similares a los previstos en el currículo de 2014 para Cultura audiovisual I y II (LOMCE).

\section{CULTURA AUDIOVISUAL (LOE, BACHILLERATO)}

\section{$1^{\circ}$ DE BACHILLERATO - OPTATIVA (en las dos modalidades de Artes:}

a) Artes plásticas, imagen y diseño

b) Artes escénicas, música y danza

BLOQUE 1. Imagen y significado

BLOQUE 2. Imagen fija y sus lenguajes

BLOQUE 3. La imagen en movimiento: el cine

BLOQUE 4. Integración de sonido e imagen. Producción multimedia

BLOQUE 5. Los medios de comunicación

BLOQUE 6. La publicidad

BLOQUE 7. Análisis de imágenes y mensajes multimedia

Tabla 2. Bloques de contenidos de la asignatura Cultura Audiovisual (LOE, Bachillerato). 
Más allá del desarrollo de los contenidos específicos y los criterios de evaluación de cada asignatura, un aspecto muy significativo de la LOGSE fueron sus objetivos, con vocación clara de educar a ciudadanos autónomos, críticos, tolerantes y solidarios (objetivos que, con pocas modificaciones, se mantuvieron en los párrafos introductorios de la LOE). En general, y como sintetiza la LOE en la presentación de la asignatura Cultura audiovisual, se trataba "de comprender, analizar y reformular la cultura visual de la sociedad en la que vivimos para comprender sus significados y como éstos afectan a las 'visiones' de nosotros mismos y de la realidad que nos rodea".

En la actual LOMCE, sin embargo, el énfasis está en otras cuestiones como en "facilitar a los alumnos y alumnas herramientas técnicas y educativas que les ayuden a gestionar la marea de datos, información, imágenes, sonidos y posibilidades creativas", aunque no excluye otros objetivos de clara vocación democrática como "servir para crear una ciudadanía más responsable, crítica y participativa", "comunicarse y conocer mejor la realidad de la cultura audiovisual" o la necesaria capacidad de "análisis" de "las características del lenguaje audiovisual desde el cual se realiza el análisis crítico de las imágenes que nos rodean".

\section{Secuenciación y planteamiento de la formación en materia audiovisual en la ESO, el Bachillerato y la EvAU (LOMCE, 2013) ${ }^{12}$}

Como antecedente claro e inmediato de esta aproximación podemos citar el informe de la Academia de las Artes y las Ciencias Cinematográficas de España (Lara, Ruíz y Tarín, 2019) y, en particular, el extenso trabajo realizado por José Manuel Pérez Tornero y Marta Portalés Oliva (2019) sobre la formación en cine en Educación Infantil, Primaria, la ESO y el Bachillerato, publicado en ese mismo volumen, y cuyos resultados y aportaciones recuperaremos parcialmente en los siguientes epígrafes. Antes, sin embargo, presentaremos la estructura actual de materias y asignaturas para entender el peso específico que tiene cada una en sus respectivos itinerarios y cursos.

En primer y segundo ciclo de la $\mathrm{ESO}^{13}$, los contenidos y competencias propios de la comunicación y la cultura audiovisual están integrados en Educación plástica, visual y audiovisual, que se imparte en los cursos $1^{\circ}, 2^{\circ}$ y $4^{\circ}$ de la ESO. La asignatura es obligatoria en $1^{\circ}$ y $2^{\circ}$ y optativa en $4^{\circ}$ curso. Como veremos, también se contemplan contenidos (y en algunos casos competencias) directamente relacionados con el audiovisual en el desarrollo curricular de otras asignaturas, como Lengua castellana y literatura, Lenguas extranjeras o Música.

En el Bachillerato, es la materia Cultura audiovisual la que recoge los contenidos y competencias que nos interesan en este análisis; es propia del itinerario de Artes y se encuentra organizada en dos asignaturas distribuidas en sus dos cursos académicos: Cultura Audiovisual I y II, siendo la segunda una de las materias específicas de las que las estudiantes pueden examinarse en la EvAU. En ambos casos, es una de las tres asignaturas trocales que se pueden elegir en la modalidad de Artes (de las tres ofertadas, las estudiantes deberán cursar dos). Como ocurre en la ESO, también en el Bachillerato otras asignaturas incorporan contenidos y competencias de formación audiovisual en sus currículos, a veces de manera muy intensa, como en Fundamentos del Arte II, asignatura troncal en el itinerario de Artes en $2^{\circ}$ de Bachillerato.

\footnotetext{
${ }^{12}$ Cuadro resumen de marcos legislativos autonómicos en Civil i Serra y Recoder Sellarés (2017: 94-98). Esquema de "Asignaturas vinculadas con comunicación, impartidas por los currículos básicos de ESO y Bachillerato, por comunidades autónomas" (en Civil i Serra y Recoder Sellarés, 2017: 99-104).

${ }^{13}$ Como es sabido, $1^{\circ}, 2^{\circ}$ y $3^{\circ}$ conforman el primer ciclo y $4^{\circ}$ de la ESO se articula como un segundo ciclo en el que las estudiantes deben elegir entre: la Opción de enseñanzas académicas para la iniciación del Bachillerato o la Opción de enseñanzas aplicadas para la Iniciación a la Formación Profesional.
} 


\section{tapbiya $\mathbf{4 8}$}

\section{El currículo audiovisual de la ESO (LOMCE, 2013)}

E| Real Decreto 1105/2014, de 26 de diciembre, por el que se establece el currículo básico de la Educación Secundaria Obligatoria y el Bachillerato señala como competencia de las administraciones el desarrollo del currículo a partir de los mínimos establecidos en dicho documento. Aquí, acotaremos el análisis a la Comunidad de Madrid14.

Como hemos expuesto, las competencias y contenidos relacionados con la formación audiovisual cobran forma en la materia Educación plástica, visual y audiovisual, obligatoria en $1^{\circ}$ y $2^{\circ}$ de la ESO y optativa en $4^{\circ}$ curso. La siguiente tabla recoge los bloques temáticos y el desarrollo de los contenidos relativos a la formación audiovisual de la materia a lo largo de los tres cursos que establece el plan de estudios:

EDUCACIÓN PLÁSTICA, VISUAL Y AUDIOVISUAL (LOMCE, ESO)

$1^{\circ} \mathrm{CICLO} / 1^{\circ}$ DE LA ESO - OBLIGATORIA

BLOQUE 1: EXPRESIÓN PLÁSTICA

BLOQUE 2: COMUNICACIÓN AUDIOVISUAL

1. Elementos de la comunicación audiovisual: emisor, receptor, mensaje, código

2. Significación de las imágenes: significante-significado: símbolos e iconos

- iconicidad

3. Elementos de la imagen y su significación: encuadre, formato y composición

4. El proceso de elaboración del mensaje audiovisual. De la imagen fija a la imagen en movimiento

5. Realización de un proyecto de animación

BLOQUE 3: DIBUJO TÉCNICO

$1^{\circ} \mathrm{CICLO} / 2^{\circ}$ DE LA ESO - OBLIGATORIA

BLOQUE 1. EXPRESIÓN PLÁSTICA

BLOQUE 2: COMUNICACIÓN AUDIOVISUAL

1. La percepción visual: las leyes de la Gestalt

2. El entorno comunicativo: iconicidad y abstracción

3. El lenguaje del cómic

4. La retórica publicitaria

5. Estructura narrativa cinematográfica

6. Análisis de las imágenes: denotación y connotación

- Lectura objetiva y subjetiva

BLOQUE 3: DIBUJO TÉCNICO

$2^{\circ} \mathrm{CICLO} / 4^{\circ}$ DE LA ESO - OPTATIVA

BLOQUE 1: EXPRESIÓN PLÁSTICA

BLOQUE 2: DIBUJO TÉCNICO

${ }^{14}$ Decreto $48 / 2015$. 
BLOQUE 3: FUNDAMENTOS DEL DISEÑO

BLOQUE 4: LENGUAIE AUDIOVISUAL Y MULTIMEDIA

1. Elementos expresivos de los lenguajes audiovisuales: encuadre, escala, angulación, iluminación

2. Elementos de la imagen en movimiento: movimientos de cámara, montaje

3. Análisis del lenguaje publicitario: tratamiento de la información y retórica del mensaje publicitario

4. El proyecto audiovisual y sus fases

5. Lectura de la imagen audiovisual

Tabla 3. Bloques de contenidos de la asignatura Educación plástica, visual y audiovisual (LOMCE, ESO).

Como se observa, los contenidos de Educación plástica, visual y audiovisual en primer ciclo están segregados de manera que en el primer curso se atiende al proceso comunicativo mismo y a la especificidad de los mensajes audiovisuales en este contexto ${ }^{15} \mathrm{y}$, en el segundo, son los diferentes medios los que estructuran la aproximación a los lenguajes (audiovisuales) del cómic, la publicidad y el cine, manteniendo la atención a los procesos de comunicación e interpretación.

En el plan de estudios para el segundo ciclo se mantienen e interrelacionan ambos ejes. Al atender a los criterios de evaluación y estándares de aprendizaje evaluables, encontramos también alusiones a las competencias prácticas que las estudiantes deben adquirir en esta asignatura. El énfasis del primer ciclo está en la especificidad de cada uno de los medios y sus lenguajes particulares, al tener que realizar fotografías, animaciones y documentos multimedia y diseñar un cómic, un mensaje publicitario y mensajes audiovisuales (recogidos de esta manera imprecisa en el currículo). Por su parte, en el segundo ciclo se orienta menos el tipo de prácticas y se amplía el terreno para la iniciativa e intereses individuales de las estudiantes (estas cuestiones figuran en el criterio 3. Realizar composiciones creativas a partir de códigos utilizados en cada lenguaje audiovisual).

Podemos recuperar algunos de los planteamientos y resultados del trabajo de José María Pérez Tornero y Marta Portalés Oliva (2019) sobre los diferentes desarrollos autonómicos del currículo de mínimos de la ESO y que articulan en base a cuatro fórmulas mediante las que el cine estaría presente en los planes de estudio: "recurso de soporte educativo", "análisis crítico del audiovisual", "producción propia de cine" y "cine como medio o forma de arte". Al poner el cine en el centro de su aproximación, el trabajo de Pérez Tornero y Portalés Oliva ofrece una interpretación del currículo distinta de la nuestra. Conforme a los cuatro criterios establecidos para su análisis comparativo, en el caso de la Comunidad de Madrid se estaría utilizando/presentando el cine como un recurso de soporte educativo, como una herramienta para el análisis crítico del audiovisual y como una forma de arte, pero en las aulas no se estaría produciendo cine: "producción propia de cine", según el elemento de la tabla. En su caso, recogen como única actividad relacionada con la producción audiovisual "la producción creativa a través de la elaboración de 'un story board a modo de guion para la secuencia de una película'"' (Pérez Tornero y Portalés Oliva, 2019: 75).

También es importante identificar y analizar la presencia que la comunicación audiovisual y la cultura audiovisual tienen en otras materias, aunque se incluyan fundamentalmente como un recurso complementario para la adquisición de conocimientos y competencias propios de la asignatura. Ocurre así en materias troncales y específicas de primer y segundo ciclo como:

${ }^{15}$ Entendemos el punto 5 del Bloque 2 (Realización de un proyecto de animación) como una primera aproximación al campo de la animación audiovisual, dado que no se contempla la formación técnicopráctica requerida para ejecutar un proyecto de esta naturaleza. 
- Lengua castellana y literatura (obligatoria en $1^{\circ}, 2^{\circ}, 3^{\circ}$ y $4^{\circ}$ de la ESO): donde aparece referida en el Bloque 1 : Comunicación oral: escuchar y hablar, en $1^{\circ}$, en relación al trabajo de interpretación de la información de los medios de comunicación audiovisuales y, en $3^{\circ}$, con respecto al "enriquecimiento de expresiones orales con apoyo de medios audiovisuales de las tecnologías de la información y la comunicación".

- Lenguas extranjeras: donde "comprender los mensajes emitidos por diferentes medios audiovisuales" se recoge como uno de los contenidos específicos.

- Y Música (obligatoria en $2^{0}$ y $3^{\circ}$ de la ESO y optativa en $4^{0}$ curso): en el currículo de $2^{\circ}$ y $4^{0}$ de la ESO, lo audiovisual está presente en los bloques 2: Escucha y 4: Música y tecnologías. La redacción y objetivos varían levemente de un curso al otro, que tienen, en cada caso, una orientación más práctica y más analítica de cada uno de los dos bloques, pero, en esencia, ambos persiguen una comprensión de la música como un elemento de lo audiovisual y de su función en este tipo de obras y un acercamiento a los procesos creativos.

Llama la atención, sin embargo, la ausencia de mención alguna al audiovisual en el currículo de la asignatura específica Artes escénicas y danza, donde podría estar presente como material de apoyo y como herramienta para configurar un marco de análisis adecuado para obras escénicas y de danza. Es de este segundo modo como aparece incluido el cine, como forma de creación audiovisual específica, en el currículo de los cuatro cursos de la materia Lengua castellana y literatura en la ESO, dentro del Bloque 4: Educación literaria.

\section{El currículo audiovisual del Bachillerato (LOMCE, 2013)}

La matrícula en la asignatura Cultura audiovisual II en $2^{\circ}$ de Bachillerato está condicionada por la superación de Cultura audiovisual I, perteneciente al curso anterior, puesto que implican continuidad. En este caso, la Comunidad de Madrid no desarrolla un currículo específico para la impartición de esta materia en la región, por lo que nos ocuparemos de los mínimos recogidos en el Real Decreto 1105/2014. Junto con el énfasis de cada Comunidad Autónoma en determinados aspectos como los que recogen en su informe Pérez Tornero y Portalés Oliva (2019), conviene subrayar cómo los cambios más sustanciales tienen que ver con el problema que Luis Fernández Colorado aborda frontalmente en su artículo para este número de Tarbiya: la imposibilidad de impartir el currículo en su totalidad durante el curso escolar y las decisiones que, con el propósito de hacerlo asequible, toman las diferentes administraciones (Fernández Colorado, 2020).

En el Boletín Oficial del Estado, la introducción a la materia ofrece una síntesis de la orientación y los objetivos en base a los cuales se han desarrollado los contenidos, criterios de evaluación y estándares de aprendizaje para Cultura audiovisual:

Esta materia pretende iniciar a los estudiantes en la fabricación de sus propias imágenes y productos audiovisuales, ya sean de naturaleza estática como la fotografía o dinámicas como el vídeo. Para esto es necesario que el alumnado esté en situación de analizar, relacionar y comprender los elementos que forman parte de la cultura audiovisual de nuestro tiempo. [...] Cultura Audiovisual se desarrolla durante dos cursos académicos, con el criterio organizador de afianzar en el primer curso de Bachillerato las habilidades y conocimientos necesarios para su desarrollo y aplicación técnica en elsegundo curso.

A pesar de lo dispuesto en la introducción y descripción de la materia Cultura audiovisual, los bloques en los que se organizan ambos cursos ponen un mayor énfasis en las competencias interpretativas, comparativas, de análisis, reconocimiento, justificación y explicación que en la aplicación de prácticas y técnicas conducentes a la creación de obras y contenidos audiovisuales. En este sentido, la orientación más teórica o más práctica de cada bloque no queda clara en los títulos, que podrían integrar ambos tipos de competencias, aunque sea claro el sesgo teórico. 
CULTURA AUDIOVISUAL. OPCIÓN DEL BLOQUE DE ASIGNATURAS TRONCALES

(LOMCE, BACHILLERATO, MODALIDAD DE ARTES)

\begin{tabular}{l}
\hline $1^{\text {O} D E ~ B A C H I L L E R A T O ~ / ~ C U L T U R A ~ A U D I O V I S U A L ~ I ~}$ \\
\hline BLOQUE 1. Imagen y sonido \\
\hline BLOQUE 2. La imagen fija y su capacidad expresiva \\
\hline BLOQUE 3. La imagen en movimiento y su capacidad expresiva \\
\hline BLOQUE 4. Narrativa audiovisual \\
\hline $2^{\circ}$ DE BACHILLERATO / CULTURA AUDIOVISUAL II \\
\hline BLOQUE 1. Integración de sonido e imagen en la creación de audiovisuales y new media \\
\hline BLOQUE 2. Características de la producción audiovisual y multimedia en los diferentes medios \\
\hline BLOQUE 3. Los medios de comunicación audiovisual \\
\hline BLOQUE 4. La publicidad \\
\hline BLOQUE 5. Análisis de imágenes y mensajes multimedia \\
\hline Tabla 4. Bloques de contenidos de la asignatura Cultura Audiovisual. Opción del bloque de asignaturas \\
troncales (LOMCE, BACHILLERATO, MODALIDAD DE ARTES)
\end{tabular}

Las competencias técnico-prácticas ocupan un lugar muy secundario tanto en el primer como en el segundo curso de Cultura audiovisual, a pesar de ser uno de los ejes sobre el que se construye este último. En el primer curso encontramos estándares de aprendizaje evaluables de carácter práctico en el Bloque 2, por ejemplo, cuyos contenidos se centran en la conceptualización de la práctica fotográfica, sus hitos históricos, elementos de composición y técnicas y sistemas de captación de imágenes y cuyos estándares se refieren a analizar, comparar, explicar, comentar, valorar y a:

- Realizar fotografías con distintas características formales (2.1)

- Realizar tratamientos digitales en blanco y negro y color (3.2)

- Realizar composiciones a color (5.1)

- Realizar composiciones con diferente intencionalidad (7.1)

También en el bloque siguiente (3. Narrativa audiovisual) se recoge entre los estándares el realizar modificaciones en piezas videográficas (5.1).

La ausencia de estándares técnico-prácticos resulta más Ilamativa, como decimos, en Cultura audiovisual II si pensamos en la orientación que la segunda parte de la asignatura tendría según lo descrito en la introducción y, en algunos casos, por los contenidos específicos que recoge cada bloque. En el primer bloque (1. Integración de sonido e imagen en la creación de audiovisuales y new media) tres de los once estándares son de este tipo y podemos resumirlos como: realizar grabaciones de sonido (2.1), realizar edición digital de sonido (3.1) y construir piezas audiovisuales (4.1). Las competencias prácticas no vuelven a mencionarse hasta el Bloque 5: Análisis de imágenes y mensajes multimedia, donde el punto 2.4 de los estándares reza "Elabora una pequeña producción audiovisual aplicando soluciones expresivas según el género y formato seleccionado". En este caso, a pesar de su indefinición, entendemos que pretende evaluar todos los conocimientos y competencias teórico-prácticas adquiridas por las estudiantes, teniendo en cuenta que aparece al final del currículo de Cultura audiovisual II. Estos estándares de orientación más práctica se adecúan, en 


\section{taphiya $\mathbf{4 8}$}

buena medida, a los contenidos de los bloques correspondientes.

Por su parte, entre los contenidos del Bloque 2: Características de la producción audiovisual y multimedia en los diferentes medios, figuran "Proceso de producción audiovisual y multimedia. Creación de imágenes en movimiento y efectos digitales. Edición y postproducción de documentos multimedia", que, sin embargo, no tienen correspondencia alguna con sus estándares de aprendizaje evaluables, que se refieren únicamente a competencias basadas en analizar, relacionar, reconocer, comparar, describir y valorar. Una orientación teórico-analítica que sí sería pertinente para evaluar los contenidos de los bloques restantes, cuyos ejes son los lenguajes, funciones e hitos de la televisión, la radio, los medios de comunicación de libre acceso y la publicidad.

En lo que respecta solo a los contenidos, hay un esfuerzo por atender a diferentes formatos audiovisuales, sus lenguajes específicos y los medios que les serían, digamos, propios o habituales, en una perspectiva histórica que, sin embargo, parece querer alejarse de una Historia del Arte general en la que pudieran integrarse (o contextualizarse, al menos) las diferentes obras audiovisuales presentes en el currículo de Cultura audiovisual. Señalamos esto por la tendencia, en cierto sentido opuesta, que encontramos en Fundamentos del Arte II (asignatura troncal de la modalidad de Artes), donde buena parte de los contenidos giran en torno a la historia del cine y los lenguajes audiovisuales que, en este caso, sí dialogan en cada uno de los bloques con otras disciplinas artísticas.

Fundamentos del arte es una materia troncal de la modalidad de Artes que se imparte en los dos cursos de Bachillerato en las asignaturas Fundamentos del Arte I y II y cuyo

objetivo principal es presentar los objetos culturales anteriores, valorarlos y conocerlos para luego poder establecer las bases de la propia idea sobre qué es la creación artística, fundamentada sobre una base de conocimientos lo más firme posible. [...] En este sentido "Fundamentos del Arte I" deberá de tener una presencia de contenidos teóricos muy importante, puesto que facilita al alumnado la base formativa inicial. Es recomendable que se incida más en el primer curso en las bellas artes tradicionales: arquitectura, pintura y escultura, puesto que son las más alejadas conceptualmente de la etapa vital de los estudiantes. Junto a esto, los contenidos del primer curso tendrán una mayor importancia cronológica en los siglos anteriores al siglo XIX. El segundo curso debe tener una parte combinativa de los elementos recibidos en el primer curso: "Fundamentos del Arte III" deberá incidir más en los siglos XIX, XX y XXI) y en las creaciones plásticas fundamentales en ellos, como son la fotografía, el cine, la televisión o la producción digital.

Con una perspectiva claramente historicista, la asignatura organiza sus bloques de manera cronológica, siendo parte del segundo curso y, por tanto, materia de examen en la EvAU, el periodo que va desde el Romanticismo hasta el presente (de 2013).

FUNDAMENTOS DEL ARTE. ASIGNATURA TRONCAL

(LOMCE, BACHILLERATO, MODALIDAD DE ARTES)

\begin{tabular}{l}
\hline $2^{\circ}$ DE BACHILLERATO / FUNDAMENTOS DEL ARTE II \\
\hline BLOQUE 1. El Romanticismo \\
\hline BLOQUE 2. El Romanticismo tardío: 1850-1900 \\
\hline BLOQUE 3. Las Vanguardias \\
\hline BLOQUE 4. Modernismo -Art Nouveau \\
\hline BLOQUE 5. El Surrealismo y otras Vanguardias
\end{tabular}

BLOQUE 6. Los Felices Años Veinte. El Art Decó 
BLOQUE 7. La Gran Depresión el Arte de su época

BLOQUE 8. La Segunda Guerra Mundial

BLOQUE 9. El Funcionalismo y las Décadas 40-50

BLOQUE 10. Los Años 60-70

BLOQUE 11. LOS Años 80-90

BLOQUE 12. Los Años 2000-2013

Tabla 5. Bloques de contenidos de la asignatura Fundamentos del Arte. Asignatura troncal (LOMCE, BACHILLERATO, MODALIDAD DE ARTES).

En este caso, los contenidos relativos al audiovisual se distribuyen en los bloques dedicados a las vanguardias (bloques 3 y 5) y los que van del bloque 7 en adelante, dedicados a las artes desde los Años 20 hasta el presente. Los contenidos se centran en la historia del cine, que se integra en esta asignatura a partir de películas y cineastas hito y movimientos 0 escuelas canónicas entre los que tienen un peso especial los casos españoles, que se presentan en contexto y diálogo con las tendencias del cine internacional en cada periodo. También, en el último bloque, se incluyen contenidos relativos al documental, la televisión y el audiovisual multimedia.

En el currículo de Bachillerato, la formación audiovisual está presente también en materias de los itinerarios de Ciencias y Ciencias Sociales. Se trata de asignaturas especializadas y con una orientación eminentemente práctica, como Imagen y sonido, una de las materias específicas de libre elección que, por pertenecer a este bloque, depende de la oferta académica de cada centro. Considerando el currículo que desarrolla para la asignatura la Comunidad de Madrid, es en esta asignatura (Imagen y sonido, de libre elección en $2^{\circ}$ de Bachillerato) donde se imparten las competencias técnicoprácticas que serían también propias del segundo curso de Cultura audiovisual.

\section{IMAGEN Y SONIDO. ASIGNATURA DE LIBRE ELECCIÓN \\ (COMUNIDAD DE MADRID, LOMCE, BACHILLERATO)}

\begin{tabular}{l}
\hline $2^{0}$ DE BACHILLERATO / IMAGEN Y SONIDO \\
\hline BLOQUE 1. Recursos expresivos utilizados en producciones audiovisuales \\
\hline BLOQUE 2. Análisis de situaciones audiovisuales \\
\hline BLOQUE 3. Elaboraciones de guiones audiovisuales \\
\hline BLOQUE 4. Captación de imágenes fotográficas y de vídeo \\
\hline BLOQUE 5. Tratamiento digital de imágenes \\
\hline BLOQUE 6. Edición de piezas visuales \\
\hline BLOQUE 7. Diseño de bandas sonoras \\
\hline BLOQUE 8. Cualidades técnicas del equipamiento de sonido idóneo en radio y medios audiovisuales \\
\hline BLOQUE 9. Equipamiento técnico en proyectos multimedia \\
\hline Tabla 6. Bloques de contenidos de la asignatura Imagen y sonido. Asignatura de libre elección \\
(COMUNIDAD DE MADRID, LOMCE, BACHILLERATO).
\end{tabular}


Al igual que ocurre en algunas asignaturas de la ESO citadas más arriba, la importancia del audiovisual es mucho más anecdótica en materias en las que aparece como apoyo y complemento para el estudio y análisis de otras manifestaciones culturales: en las asignaturas Literatura Universal (materia de opción de los bloques de Humanidades y Ciencias Sociales y Artes en $1^{\circ}$ de Bachillerato), Historia del Arte (materia de opción de bloque del itinerario de Humanidades y Ciencias Sociales en $2^{\circ}$ de Bachillerato) e Historia de la Música y la Danza (asignatura específica de $2^{\circ}$ de Bachillerato, que se oferta o no dependiendo de cada centro).

Por último, conviene también atender desde una perspectiva de género a los contenidos de las materias analizadas. En Cultura Audiovisual, como abunda Luis Fernández Colorado en su contribución a este monográfico, "las referencias nominales dentro de los contenidos no recogen la presencia de mujeres" cineastas, y apenas citan tres fotógrafas: Ouka Lele, Cristina García Rodero y Dorothea Lange (Fernández Colorado, 2020). Se trata de una cuestión a la que algunas comunidades autónomas han querido dar solución con diversas fórmulas:

La temática de la igualdad del género a través de la representación de la mujer en el cine y en la propia industria cinematográfica tiene presencia a nivel nacional, sin embargo, tan solo se destaca el trabajo de tres directoras de cine, frente al resto de toda la filmografía propuesta. La perspectiva de género es adoptada y ampliada principalmente por Andalucía y Canarias. También se nombran los esfuerzos de las compositoras en las bandas sonoras, pero tan solo en Asturias e Islas Canarias. (Pérez Tornero y Portalés Oliva, 2019: 120)16

El problema de la proporcionalidad, la representatividad, la visibilidad y la inclusión de mujeres en el canon, en este caso de artistas y creadorxs, superan el marco de la educación secundaria y los currículos que nos ocupan en este informe. Sin embargo, este es un ámbito en el que la ausencia de referentes no masculinos resulta especialmente significativa y un problema para el que urge buscar soluciones (sobre todo ahora, en vísperas de una nueva Ley de Educación).

\section{El acceso a los estudios superiores desde Cultura Audiovisual y la EvAU}

En nuestro planteamiento, nos interesa la relación directa que se establece entre el Bachillerato, la EvAU y los estudios universitarios de Grado en base a las calificaciones de las estudiantes y las modalidades en las que se integran las materias del Bachillerato y las áreas de cada uno de los grados universitarios. También, nos preocupan las relaciones y tensiones que se establecen con los programas de Formación Profesional vinculados al audiovisual (García Domínguez, 2020) y el hecho de que Cultura audiovisual sea una de las materias específicas de las que las estudiantes pueden examinarse en la EvAU.

La cuestión misma aparece ya enunciada en el currículo de Cultura audiovisual en la LOMCE, que expone:

Esta materia tiene un carácter propedéutico necesario y básico para su desarrollo en etapas posteriores, ya sea en estudios universitarios de comunicación audiovisual y publicidad, bellas artes (entre otros); como para los de formación profesional de imagen y sonido y enseñanzas artísticas. [...] En este sentido, la enseñanza de esta materia se estructura en dos caminos paralelos y complementarios. El primero de ellos es el análisis de los productos que se presentan por medios digitales. Aprender a ver, a escuchar, a discernir lo que se dice, cómo se dice y por qué se presenta al espectador de una manera determinada. [...] El segundo de ellos es la creación por parte del alumnado de productos audiovisuales ${ }^{17}$.

\footnotetext{
${ }^{16}$ También señalan el énfasis del currículo de Canarias para Fundamentos del arte en esta misma dirección (Pérez Tornero y Portalés Oliva, 2019: 105).

${ }^{17}$ Real Decreto 1105/2014, p. 227.
} 
Como ya hemos visto, los contenidos y competencias técnico-prácticas que recoge este mismo documento para los dos cursos de Cultura audiovisual son muy limitados, primando, en todo momento, el desarrollo de las capacidades críticas y analíticas de las estudiantes durante los dos cursos en los que se imparte esta materia. Este hecho nos lleva a cuestionar el carácter propedéutico real de esta materia a la hora de incorporarse a una u otra de las vías formativas posibles y a preguntarnos si las competencias y conocimientos adquiridos tienen el mismo grado de adecuación a los que se recogen en los currículos de un grado en Comunicación audiovisual, en Bellas Artes o en Imagen y sonido, del ámbito de la Formación Profesional.

Al mirar el desarrollo del currículo y los temarios de algunos libros de texto para Cultura audiovisual ${ }^{18}$, donde la orientación de estos y su organización en temas y bloques específicos resulta más clara, encontramos que son los medios de comunicación clásicos (cine, radio, televisión, multimedia-internet), sus lenguajes, problemáticas, hitos e historias los que articulan la asignatura. A la hora de pensar sus esquemas y su pertenencia a un contexto más amplio, vemos que el diseño de la asignatura se basa en el sistema y la estructura de medios de comunicación, primando una aproximación al audiovisual en tanto que industria cultural y mediática y relegando otros acercamientos posibles que acentúen su condición de expresión artística.

Este último punto llama especialmente la atención al tratarse de una materia, Cultura audiovisual, inscrita en el itinerario de Artes del Bachillerato y no en el de Ciencias Sociales, rama disciplinar a la que sí pertenecen, en el ámbito universitario, los estudios de Comunicación audiovisual, con cuya programación esta materia guarda estrechas semejanzas. También llama la atención la poca sintonía que, sobre el papel, parece existir entre los dos cursos de Cultura audiovisual y Fundamentos del arte II en el sentido en que enfrentan desde posiciones muy distintas la creación cinematográfica y audiovisual: en el marco de la Comunicación audiovisual, como hemos dicho, y entendiendo el cine como una disciplina artística, en el segundo caso, con una orientación más cercana a la que puede tener un grado en Historia del arte.

Existen, del mismo modo, algunas tensiones con respecto a la formación técnico-práctica que resultaría especialmente pertinente para cursar estudios de grado en Bellas Artes o Formación Profesional en Imagen y sonido y que no tendrían un peso suficiente en el desarrollo curricular de Cultura audiovisual I, ni II, donde el acento debería estar, precisamente, en el desarrollo de estas competencias prácticas.

Las adscripciones disciplinares mencionadas, así como la formación y especialización de las profesoras y el carácter más teórico o práctico del contenido de las asignaturas también condiciona el perfil de las docentes que las imparten y, esto, a su vez, afecta a la orientación, competencias y contenidos que finalmente se atienden durante el curso. En su trabajo sobre Comunicación en la ESO y el Bachillerato en España, Marta Civil i Serra y María José Recader señalan que la mayoría de universidades que imparten los estudios de Máster que habilitan para la docencia en la ESO, Bachillerato y Formación Profesional ofrecen las especialidades de las materias obligatorias en ESO y Bachillerato, pero hay muy pocos centros en los que seguir las especialidades de materias como Dibujo o Cultura clásica y señalan, además, la falta de una especialidad en "Comunicación" o similar (Civil i Serra y Recader, 2017: 105). Esto afectaría, por un lado, a las posibilidades de acceso de especialistas a la impartición de materias de Comunicación, pero, al mismo tiempo, al perfil de los docentes que, provenientes de otros grados, acabarían impartiendo estas asignaturas en la ESO y el Bachillerato.

Con respecto a la EvAU, y como es sabido, la fórmula para la nota de admisión a los grados universitarios consiste en un 60\% la nota media del Bachillerato, un 40\% la media de la fase general y la suma de dos notas de la fase específica multiplicadas por 0,1 o por 0,2 (en caso de que la universidad considere la asignatura idónea para el desarrollo de los estudios en un Grado en particular). Aś, independientemente de la orientación y los contenidos y competencias más en

\footnotetext{
${ }^{18}$ En el caso de la asignatura Cultura audiovisual de la LOE (Arroyo Almaraz, 2012) y de Cultura audiovisual II de la LOMCE (Castillo, 2017).
} 
línea con los estudios de Comunicación audiovisual, la asignatura Cultura audiovisual II sería idónea para grados como Bellas Artes 0 Historia del arte, además de para los verdaderamente afines de Comunicación audiovisual, Periodismo y Publicidad ${ }^{19}$. En este sentido, existirían sintonías y desajustes en la transición del Bachillerato a la universidad 0 a la Formación Profesional y entre asignaturas y grados articulados en torno a lo audiovisual adscritos a diferentes áreas y disciplinas. Podríamos entender esto como una dificultad o como una manera de incorporar o apuntalar determinados conocimientos y competencias que quedan relegados a un segundo plano en los estudios de grado: pensemos, por ejemplo, en los contenidos relativos a las estructuras del sistema de medios de comunicación impartidos en el Bachillerato que quedan al margen de los planes de estudios de Historia del arte o Bellas Artes, pero que permitirían a las estudiantes conectar "su" sistema del arte con los contextos de producción y circulación cultural "del" ámbito de la comunicación.

\section{... esperando la LOMLOE}

Como hemos visto en este recorrido, el audiovisual parece estar más presente que nunca; y quizá lo está en determinados itinerarios formativos como las opciones de Bachillerato de Artes (en la asignatura Cultura audiovisual I y II) y Humanidades y Ciencias Sociales (en Historia del Arte), fundamentalmente, pero su importancia sigue siendo relativa en la ESO y se limita a la asignatura optativa Imagen y sonido en el de Bachillerato de Ciencias (asignatura cuya oferta depende de las administraciones autonómicas y los centros). En todo caso, ni siquiera las asignaturas de comunicación audiovisual y cultura audiovisual son o han sido obligatorias en los itinerarios de los que forman parte como materias de modalidad: en ninguno de los tres planes analizados (Comunicación audiovisual era optativa del Bachillerato Tecnológico y de Humanidades y Ciencias Sociales en la LOGSE, Cultura audiovisual era elegible en las dos modalidades de Artes de la LOE y Cultura audiovisual I y II son elegibles en la modalidad de Artes de la LOMCE).

Por otro lado, y a pesar de su inclusión como material complementario y objeto de trabajo y análisis en asignaturas relacionadas con las lenguas, la música, la danza y la literatura, la alfabetización y las competencias de interpretación y expresión audiovisuales no están entre los objetivos básicos y transversales de los actuales planes de estudios.

En este punto, con un previsible cambio de mano de la LOMLOE a la vuelta de la esquina, el debate en la educación secundaria, obligatoria y posobligatoria, debe centrarse, más allá de en la creación de asignaturas que de manera específica atiendan a contenidos y competencias relacionadas con lo audiovisual y en algunos de los problemas expuestos en estas páginas, en incorporar la alfabetización en este campo como un contenido básico y transversal de los planes de estudios: entendiéndola, y poniéndola en valor, como una herramienta que contribuya a la educación de ciudadanos críticos capaces de interpretar, analizar, describir, expresar, diseñar, registrar, explicar, componer, relacionar, valorar, pensar, crear, etc. vivencias, opiniones e ideas, en línea con lo que los objetivos de esta etapa formativa ya enumeran. En este sentido, podemos señalar una de las modificaciones que se prevén en la LOMLOE y

\footnotetext{
${ }^{19}$ Según el cuadro de ponderaciones de la Universidad Complutense de Madrid para el acceso al curso 2020/2021, Cultura audiovisual II sería materia idónea para obtener la nota de acceso a 6 de los 17 Grados que oferta esta universidad en la rama de Artes y Humanidades y a 11 de los 28 de la rama de Ciencias Sociales y Jurídicas: para los grados en Bellas Artes, Conservación y restauración del patrimonio cultural, Diseño, Filosofía, Historia, Historia del Arte, Comunicación audiovisual, Criminología, Educación social, Información y documentación, Maestro en educación infantil, Maestro en educación primaria, Pedagogía, Periodismo, Publicidad y relaciones públicas, Relaciones internacionales y Sociología (UCM, 2020). En la EvAU 2019 se matricularon un total de 30.197 estudiantes en la Comunidad de Madrid, de los cuales 1.107 pertenecían a la modalidad de Artes. Del total de 30.197 matriculados en la prueba general, 5.336 se presentaron a una asignatura del bloque específico, 18.502 a dos asignaturas, 5.414 a tres y 262 al máximo de cuatro asignaturas (EvAU 2019).
} 


\section{tapbiya $\mathbf{4 8}$}

que es a la vez un síntoma de vitalidad del debate sobre la alfabetización audiovisual como una competencia transversal:

5. Sin perjuicio de su tratamiento específico, la comprensión lectora, la expresión oral y escrita, la comunicación audiovisual, la competencia digital, el emprendimiento social y empresarial, el fomento del espíritu crítico y cientifico, la educación emocional y en valores y la creatividad se trabajarán en todas las materias. En todo caso se fomentarán de manera trasversal la educación para la salud, incluida la afectivo-sexual, la formación estética, la igualdad de género y el respeto mutuo y la cooperación entre iguales. (LOMLOE, Proyecto de Ley Orgánica, modificación del Artículo 24 de la LOE) 


\section{Anexos}

\section{EDUCACIÓN PLÁSTICA Y VISUAL (LOGSE, ESO)}

\begin{tabular}{|c|}
\hline $1^{\circ}$ DE LA ESO - OBLIGATORIA \\
\hline BLOQUE 1. Elementos configurativos de los lenguajes visuales \\
\hline BLOQUE 2. Representación de formas planas \\
\hline BLOQUE 3. Espacio y volumen \\
\hline BLOQUE 4. Procedimientos y técnicas utilizadas en los lenguajes visuales \\
\hline $2^{\circ}$ DE LA ESO - OBLIGATORIA \\
\hline BLOQUE 1. El lenguaje visual \\
\hline BLOQUE 2. Elementos configurativos de los lenguajes visuales \\
\hline BLOQUE 3. Representación de formas planas \\
\hline BLOQUE 4. Espacio y volumen \\
\hline BLOQUE 5. Procedimientos y técnicas utilizadas en los lenguajes visuales \\
\hline $3^{\circ}$ DE LA ESO - OBLIGATORIA \\
\hline BLOQUE 1. El lenguaje visual \\
\hline BLOQUE 2. Elementos configurativos de los lenguajes visuales \\
\hline BLOQUE 3. Análisis y representación de formas \\
\hline BLOQUE 4. La composición \\
\hline BLOQUE 5. Espacio y volumen \\
\hline BLOQUE 6. Procedimientos y técnicas utilizados en los lenguajes audiovisuales \\
\hline BLOQUE 7. Apreciación del proceso de creación de las artes visuales \\
\hline $4^{\circ}$ DE LA ESO - OPTATIVA (a elegir 2 entre 5) \\
\hline BLOQUE 1. El lenguaje visual \\
\hline BLOQUE 2. Los elementos gráfico-plásticos como vehículo para el análisis y creación de imágenes \\
\hline BLOQUE 3. Análisis y representación de formas \\
\hline BLOQUE 4. La composición \\
\hline BLOQUE 5. Percepción y representación \\
\hline BLOQUE 6. Procedimientos y técnicas empleados en los lenguajes visuales \\
\hline BLOQUE 7. Proceso de creación \\
\hline
\end{tabular}




\section{tapbiya $\mathbf{4 8}$}

COMUNICACIÓN AUDIOVISUAL (LOGSE, BACHILLERATO)

$1^{\circ}$ DE BACHILLERATO - OPTATIVA

(en las opciones de Bachillerato Tecnológico [1 optativa de 5 posibles] y de las dos modalidades de Humanidades y Ciencias Sociales [1 de 4])

BLOQUE 1. Las tecnologías audiovisuales

BLOQUE 2. Los nuevos desarrollos tecnológicos

BLOQUE 3. La comunicación audiovisual

BLOQUE 4. Los lenguajes audiovisuales

BLOQUE 5. Tecnologías audiovisuales y realidad

\section{EDUCACIÓN PLÁSTICAY VISUAL (LOE, ESO)}

$1^{\circ}, 2^{\circ} 0$ ó $3^{\circ}$ ESO - OBLIGATORIA (en uno de los tres primeros cursos de la ESO)

BLOQUE 1. Observación

BLOQUE 2. Experimentación y descubrimiento

BLOQUE 3. Entorno audiovisual y multimedia

- Identificación del lenguaje visual y plástico en prensa, publicidad y televisión. Estudio y experimentación a través de los procesos, técnicas y procedimientos propios de la fotografía, el vídeo y el cine, para producir mensajes visuales.

- Experimentación y utilización de recursos informáticos y las tecnologías para la búsqueda y creación de imágenes plásticas.

- Actitud crítica ante las necesidades de consumo creadas por la publicidad y rechazo de los elementos de la misma que suponen discriminación sexual, social o racial.

- Reconocimiento y valoración del papel de la imagen en nuestro tiempo.

BLOQUE 4. Expresión y creación

BLOQUE 5. Lectura y valoración de los referentes artísticos

$4^{0}$ DE LA ESO - OPTATIVA

(elegir entre tres opciones/itinerarios con tres asignaturas cada una: se puede cursar una opción completa 0 dos asignaturas de una opción y la tercera de una opción diferente)

BLOQUE 1. Procesos comunes a la creación artística

BLOQUE 2. Expresión plástica y visual

BLOQUE 3. Artes gráficas y diseño

BLOQUE 4. Imagen y sonido

- Técnicas de expresión gráfico-plásticas aplicadas a la animación e interactividad

- Reconocimiento y lectura de imágenes de video y multimedia

- Sintaxis del lenguaje cinematográfico y videográfico

- Aplicación de la imagen animada en formas multimedia 


\section{tarbiya $\mathbf{4 8}$}

\section{Normativa citada}

Decreto 34/2002, de 7 de febrero, por el que se aprueba el currículo de las áreas de conocimiento y materias obligatorias y opcionales de la Educación Secundaria Obligatoria para la Comunidad de Madrid.

http://www.madrid.org/wleg_pub/secure/normativas/contenidoNormativa.jsfopcion=VerHtmllnfo\&idnorma=4207\#no-back-b utton

Decreto 48/2015, de 14 de mayo, del Consejo de Gobierno, por el que se establece para la Comunidad de Madrid el currículo de la Educación Secundaria Obligatoria.

https://www.bocm.es/boletin/CM_Orden_BOCM/2015/05/20/BOCM-20150520-1.PDF

Ley Orgánica 1/1990, de 3 de octubre de 1990, de Ordenación General del Sistema Educativo (LOGSE).

https://www.boe.es/diario_boe/txt.php?id=BOE-A-1990-24172

Ley Orgánica 2/2006, de 3 de mayo, de Educación (LOE).

https://www.boe.es/diario_boe/txt.php?id=BOE-A-2006-7899

Ley Orgánica 8/2013, de 9 de diciembre, para la mejora de la calidad educativa (LOMCE).

https://www.boe.es/buscar/pdf/2013/BOE-A-2013-12886-consolidado.pdf

Proyecto de Ley Orgánica por la que se modifica la Ley Orgánica 2/2006, de 3 de mayo, de Educación, de 25 de noviembre de 2020 (LOMLOE).

https://www.educacionyfp.gob.es/dam/jcr:f19685f1-0260-4926-b043-768d82ed09e0/bocg-d-14-113-983-senado.pdf

Real Decreto 1007/1991, de 14 de junio, por el que se establecen las enseñanzas mínimas correspondientes a la Educación Secundaria Obligatoria.

https://www.boe.es/buscar/doc.php?id=BOE-A-1991-16422

Real Decreto 1631/2006, de 29 de diciembre, por el que se establecen las enseñanzas mínimas correspondientes a la Educación Secundaria Obligatoria.

https://www.boe.es/buscar/pdf/2007/BOE-A-2007-238-consolidado.pdf

Real Decreto 1467/2007, de 2 de noviembre, por el que se establece la estructura del bachillerato y se fijan sus enseñanzas mínimas, para la Ley Orgánica 2/2006, de 3 de mayo, de Educación (LOE).

https://www.boe.es/boe/dias/2007/11/06/pdfs/A45381-45477.pdf

Real Decreto 1892/2008, de 14 de noviembre, por el que se regulan las condiciones para el acceso a las enseñanzas universitarias oficiales de grado y los procedimientos de admisión a las universidades públicas españolas.

https://www.boe.es/buscar/act.php?id=BOE-A-2008-18947

Real Decreto 1105/2014, de 26 de diciembre, por el que se establece el currículo básico de la Educación Secundaria Obligatoria y el Bachillerato.

https://www.boe.es/boe/dias/2015/01/03/pdfs/BOE-A-2015-37.pdf

Resolución de 29 de diciembre de 1992, de la Dirección General de Renovación Pedagógica, por la que se regula el currículo de las materias optativas de Bachillerato establecidas en la Orden de 12 de noviembre de 1992 de implantación anticipada del Bachillerato definido por la Ley Orgánica 1/1990, de 3 de octubre de 1990, de Ordenación General del Sistema Educativo (LOGSE).

https://www.boe.es/buscar/doc.php?id=BOE-A-1993-2192 


\section{Bibliografía}

Alonso, F. (2002). El cine como asignatura en el Bachillerato. Tarbiya. Revista de investigación e innovación educativa, 31, 107-114.

https://revistas.uam.es/tarbiya/article/view/7400

ArRoyo Almaraz, I. (2012). Cultura audiovisual. Madrid: Ediciones del laberinto.

CASTILLO, J. M. (2017). Cultura audiovisual II. Madrid: Ediciones Paraninfo.

CiviL I SeRRA, M. y ReCOder Sellarés, M. J. (2017). El papel de la comunicación en ESO y Bachillerato en España (2017). El caso de las asignaturas implantadas en el marco de la LOMCE. En I. Postigo y M. J. Recoder (coords.): Los y las "tics" en los estudios de comunicación. Asociación de Universidades con Titulaciones de Información y Comunicación (ATIC), 85-110.

http://titulaciones-atic.com/wp-content/uploads/2016/05/Los-y-las-tics-en-estudios-de-comunicacion-ATIC.pdf

EvaU (2019). Presentación de resultados. Universidades públicas de Madrid. Dirección General de Universidades de la Comunidad de Madrid.

https://www.comunidad.madrid/sites/default/files/doc/educacion/univ/rueda_de_pensa_evau_2019.pdf

Fernández Colorado, L. (2020). En torno al currículo de Cultura Audiovisual en el Bachillerato: una reflexión crítica. Tarbiya. Revista de investigación e innovación educativa, 48.

https://revistas.uam.es/tarbiya/issue/archive

García Domínguez, L. (2020). Cultura Audiovisual en la Formación Profesional del Sistema Educativo. Tarbiya. Revista de investigación e innovación educativa, 48.

https://revistas.uam.es/tarbiya/issue/archive

Lara, Fernando; Ruíz, Mercedes y Tarín, Marta (CoORds.) (2019). Cine y educación. Documento marco para el proyecto pedagógico impulsado por la Academia de las Artes y las Ciencias Cinematográficas de España. Madrid: Academia de las Artes y las Ciencias Cinematográficas de España.

https://www.academiadecine.com/wp-content/uploads/2019/03/Cine-y-Educacio\%CC\%81n.pdf

SALVADOR, A. (2002). La comunicación audiovisual desde la perspectiva de la Historia y de las Ciencias Sociales. Tarbiya. Revista de investigación e innovación educativa, 31, 115-139.

https://revistas.uam.es/tarbiya/article/view/7401

PÉrez TORnero, J. M. y Portalés Oliva, Marta (2019). El cine en el sistema educativo español. Informe de investigación. En F. Lara, M. Ruiz y M. Tarín (coords.): Cine y educación. Documento marco para el proyecto pedagógico impulsado por la Academia de las Artes y las Ciencias Cinematográficas de España. Madrid: Academia de las Artes y las Ciencias Cinematográficas de España, 39-146.

https://www.academiadecine.com/wp-content/uploads/2019/03/Cine-y-Educacio\%cc\%81n.pdf

UCM, UniveRSIDAD COMPLUTENSE de MADRID (2020). Cuadro de ponderaciones 2020-2021.

https://www.ucm.es/data/cont/docs/3-2020-02-03-Cuadro\%20Ponderaciones\%202020-2021\%20C0N\%20ADE\%20

y\%20Econom\%C3\%ADa\%20en\%20ingl\%C3\%A9s.pdf 


\section{tgphiyg $\mathbf{4 8}$}

\section{Resumen.}

Este artículo analiza la presencia que contenidos y competencias vinculadas a la comunicación y la cultura audiovisuales han tenido en la educación secundaria en España desde que, en 1990, la Ley Orgánica de Ordenación General del Sistema Educativo (LOGSE) estableciera el modelo y la estructura actuales.

Palabras clave. Bachillerato; Educación Secundaria Obligatoria; Cultura audiovisual; Comunicación audiovisual; Educación plástica visual y audiovisual; Imagen y sonido; LOGSE; LOE; LOMCE.

\section{Abstract.}

This article analyses how contents and competencies associated to communication and audiovisual culture are integrated in the Spanish Secondary Education's plan. The current model and structure were approved in 1990 by the Law Ley Orgánica de Ordenación General del Sistema Educativo (LOGSE).

Key-words. Baccalaureate; Compulsory Secondary Education; Audiovisual Culture; Media Studies; Plastic Visual and Audiovisual Education; Image and Sound; LOGSE; LOE; LOMCE.

Minerva Campos Rabadán

IUCE. Universidad Autónoma de Madrid minerva.campos.rabadan@gmail.com 